\title{
Automatic Procedure to Determine Acidity in Fuel Ethanol by Photometric Titration Using Binary Search and Multicommuted Flow Analysis
}

\author{
Manoel J. A. Lima ${ }^{a}$ and Boaventura F. Reis $*, a$ \\ ${ }^{a}$ Centro de Energia Nuclear na Agricultura, Universidade de São Paulo, \\ Avenida Centenário, 303, 13416-000 Piracicaba-SP, Brazil
}

\begin{abstract}
An automatic photometric titration procedure was developed to determine the acidity of fuel ethanol. The procedure was implemented by using a binary search algorithm and a multicommuted flow analysis approach. Solution-handling setup included a homemade syringe pump and a set of solenoid valves, which were assembled to treat the solution-handling as a time function controlled by a microcomputer. Photometer detection was performed using a compact homemade light emitting diode (LED)-based photometer. Aiming to evaluate the accuracy, samples were analyzed by employing the methodologies recommended by the Brazilian Association of Technical Standards (ABNT) and the American Society for Testing and Materials (ASTM). Accuracy was assessed by applying the Student's $t$-test for paired samples at the $95 \%$ confidence level $(n=4)$, which shown that there is no significant difference between results. Other useful features included relative standard deviation of $<1 \%$ and waste generation volume ten times lower than those produced by ABNT and ASTM methods.
\end{abstract}

Keywords: fuel ethanol, syringe pump, multicommuted flow analysis, spectrophotometric titration, LED-based photometer

\section{Introduction}

Biofuels are renewable energy sources. The main types of biofuels are biomass, bioethanol, biodiesel, and biogas. Plants are the main suppliers of raw materials necessary to produce biofuels. Burning fuels releases $\mathrm{CO}_{2}$, which is removed from the environment by plants via photosynthesis. As a result, the use of biofuels has recently become more attractive in accordance with the current environmental demands. ${ }^{1}$ Biofuels have been proposed as an alternative energy matrix to non-renewable sources (e.g., petroleum, coal, and natural gas). One of the most common biofuels is bioethanol (ethanol), which is mainly produced from raw materials such as corn, wheat, sugarcane, beet, and manioc using conversion technologies. ${ }^{2}$ Ethanol used as fuel is produced mainly from corn by the United States ( $>54.3$ billion liters per year) and from sugarcane in Brazil (29.9 billion liters in 2016), which are responsible for about $70 \%$ of world production. The Brazilian production of ethanol from sugarcane has the advantages of high productivity per hectare, shorter fermentation time, and by-products with higher added value. ${ }^{3,4}$

*e-mail: reis@cena.usp.br
Some countries add anhydrous ethanol in gasoline at a ratio of $10 \%(\mathrm{v} / \mathrm{v})$, while in Brazil, the ratio is $27 \%(\mathrm{v} / \mathrm{v})$ for common gasoline. Furthermore, in Brazil, hydrated ethanol (95\% ethanol, 5\% water) is used on a large scale as a vehicular fuel. In addition, its high heat of vaporization and octane number add to ethanol considerable environmental advantages over non-renewable fuels.

Despite the advantages of ethanol usage in total or partial replacement of fossil fuels, the high corrosive potential associated with the quality of ethanol is considered the main problem. Fuel ethanol may have inorganic contaminants due to the production processes, storage, and transportation, which could cause corrosion in the engine and the injection system..$^{5-7}$ The acidity and the presence of inorganic species (e.g., $\mathrm{Cl}^{-}, \mathrm{Cu}^{2+}, \mathrm{Fe}^{3+}$, and $\mathrm{SO}_{4}{ }^{2-}$ ), combined with free oxygen are responsible for the induction of the main corrosive processes caused by fuel ethanol.

Considering the corrosion potential, government agencies have established concentration limits for corrosive chemical species in fuel ethanol. To control acidity, samples are generally analyzed by volumetric titration. In Brazil, the ANP (Agência Nacional do Petróleo, Gás Natural e Biocombustíveis) established the ABNT (Associação 
Brasileira de Normas Técnicas) NBR 9866 resolution $^{8}$ (2012) as the official methodology. The method is based on the neutralization titration with visual end-point observation, using $\alpha$-naphtholphthalein as a color indicator. The American Society for Testing and Materials (ASTM) established the D1613-17, ${ }^{9}$ a standard method to determine the acidity of solvents, including ethanol. The method is based on the neutralization titration with visual end-point observation, using phenolphthalein as an indicator. Both methods require stepwise handling of the titration solutions, usually performed manually, consuming large volumes of solutions and demanding long time for its finalization. The visual detection of the titration end-point could become a source of error, which could be prevented by employing an automated setup with the ability to handle the titration solution and detect the end-point of the titration. Both regulatory agencies consider $30 \mathrm{mg}$ acetic acid per liter of fuel as the maximum acceptable amount.

From an overview on the literature, only three papers related with the acidity determination in fuel ethanol were found, employing as detection techniques conductometry ${ }^{10,11}$ and coulometry, ${ }^{12}$ which were implemented using batch stepwise ${ }^{11,12}$ and flow analysis approach. ${ }^{10}$ However, for other analytes a number of papers were found. ${ }^{13,14}$

In this work, we propose a fully automatic analytical procedure for the determination of total acidity in fuel ethanol, employing photometric titration. The procedure is implemented by a binary search algorithm, ${ }^{15}$ accomplished by employing a multicommuted flow analysis setup and a homemade light emitting diode (LED)-based photometer. A multicommuted flow analysis setup assembled with solenoid valves to act as an individual commutating unit, affords facility to handle little volumes of solution without lessening the precision. ${ }^{16-19}$ This facility is exploited in this work in order to develop a fully automatic photometric titration procedure.

\section{Experimental}

\section{Reagents and solutions}

All solutions were prepared with purified water with a resistivity value greater than $18 \mathrm{M} \Omega \mathrm{cm}$ at $25^{\circ} \mathrm{C}$ (Millipore Milli-Q system) and analytic grade reagents. All solutions were prepared using pre-boiled water that was cooled to the room temperature prior to use.

Sodium hydroxide stock solution (Merck, > 99\%) of $1.0 \mathrm{~mol} \mathrm{~L}^{-1}$ was prepared by dissolving the solids in water. Working solutions were prepared by diluting it with water and standardized with biphthalate (Merck, > 99\%) (previously dried in an oven and stored in a desiccator) and using phenolphthalein as an indicator. A $0.5 \mathrm{~mol} \mathrm{~L}^{-1}$ acetic acid stock solution (Merck, $>99 \%$ ) and a $0.5 \mathrm{~mol} \mathrm{~L}^{-1}$ hydrochloric acid solution (Merck, $>37 \%$ ) were prepared by diluting the concentrated stocks with water and they were stored in amber glass vials. A $1.0 \%(\mathrm{~m} / \mathrm{v})$ stock solution of $\alpha$-naphtholphthalein (3,3-bis(4-hydroxy1-naphthyl)phthalide) (Sigma-Aldrich, > 99\%) and a $1.0 \%(\mathrm{~m} / \mathrm{v})$ phenolphthalein (3,3-bis(4-hydroxyphenyl)$1(3 H)$-isobenzofuranone) were prepared in $70 \%(\mathrm{v} / \mathrm{v})$ ethanol solutions. Prior to use, appropriate dilutions were performed with a $50 \%(\mathrm{v} / \mathrm{v})$ ethanol solution.

Samples were prepared as follows: a water aliquot of $5 \mathrm{~mL}$ and $10 \mu \mathrm{L}$ of $\mathrm{NaOH}\left(10.0 \mathrm{mmol} \mathrm{L}^{-1}\right)$ were added to a volumetric flask $(10 \mathrm{~mL})$. Then, a sample aliquot $(5 \mathrm{~mL})$ was added to the flask using a volumetric pipette. After shaking gently, the volume was increased to $10 \mathrm{~mL}$ by adding water.

\section{Equipment and accessories}

To carry out the batch titrations, a burette with a volume of $5.00 \mathrm{~mL}$ and graduation range of $0.01 \mathrm{~mL}$ was used. The mixing was performed using a magnetic stirrer bar. Class A glassware was used in the experiments.

The equipment setup consisted of two distinct parts: a system for solution-manipulation and a system for photometric detection. A syringe pump prototype was used for the propulsion of solutions and consisted of two glass syringes (Arti Glass, $5 \mathrm{~mL}$ ), ${ }^{20}$ two three-way solenoid valves (HP225T031, 100 psi, NResearch), and four two-way solenoid valves (normally closed) (161T011, 30 psi, NResearch). Flow lines and sampling loop were of polytetrafluoroethylene (PTFE) tubes with $0.8 \mathrm{~mm}$ i.d. The control of the syringe pump and flow analysis module were performed employing a microcomputer equipped with a PCL711 (Advantech) interface card and a software written in Quick BASIC 4.5. The detection setup comprised a photodetector OPT301 (Texas Instruments), two LEDs with high-intensity emission beams ( $\lambda_{\max } 647$ or $530 \mathrm{~nm}$ ) and a flow cell with an optical path of $50 \mathrm{~mm}$, as described elsewhere. ${ }^{21}$

\section{ABNT method (NBR 9866.2012) ${ }^{8}$}

The assays employing the ABNT method were performed as follows: firstly, $50 \mathrm{~mL}$ water and $100 \mu \mathrm{L}$ of $\alpha$-naphtholphthalein indicators $(1 \%, \mathrm{~m} / \mathrm{v})$ were added to an Erlenmeyer flask $(250 \mathrm{~mL})$. The solution was neutralized under constant stirring using a standardized $\mathrm{NaOH}$ solution (10.0 $\left.\mathrm{mmol} \mathrm{L}^{-1}\right)$. Afterward, a $50 \mathrm{~mL}$ aliquot of the sample was added to the Erlenmeyer flask. The titrant was added 
to the titration vessel stepwise and stirred until a blue color appeared. ${ }^{8}$

\section{ASTM method (D1613-17) ${ }^{9}$}

The assays employing the ASTM method were performed as follows: firstly, $50 \mathrm{~mL}$ water and $0.5 \mathrm{~mL}$ of phenolphthalein indicator $(1 \%, \mathrm{~m} / \mathrm{v})$ were added to an Erlenmeyer flask $(250 \mathrm{~mL})$ and were neutralized using a standard $\mathrm{NaOH}$ solution (10.0 mmol L-1). Afterward, a sample aliquot $(50 \mathrm{~mL})$ was added to the Erlenmeyer flask. The titrant $\left(\mathrm{NaOH}, 10.0 \mathrm{mmol} \mathrm{L}^{-1}\right)$ was added to the titration vessel stepwise and stirred until a pink color appeared. Prior to beginning the titration, nitrogen gas was bubbled into the sample to remove $\mathrm{CO}_{2}$ from the bulk sample. ${ }^{9}$

\section{Description of the procedure}

The flow analysis module comprises a syringe pump for fluid propulsion and a set of solenoid valves to handle the solutions. The flow diagram is shown in Figure 1 at the standby condition.

The control software was designed to perform the photometric titration procedure, employing the binary search algorithm. ${ }^{15}$ When the software begins the first titration run, the syringe pump is set to work at the aspiration mode and the solenoid valve $V_{1}$ was maintained switched on, while solenoid valves $\mathrm{V}_{3}, \mathrm{~V}_{4}$, and $\mathrm{V}_{5}$ were sequentially switched on/off. Under these conditions, the sampling loop $\left(\mathrm{L}_{1}\right)$ is loaded with a string comprising slugs of sample in tandem with the slugs of the titrant and the color indicator solutions.

To perform the sampling step, the flow rate was set at $25.0 \mu \mathrm{L} \mathrm{s}^{-1}$ and the time intervals for solenoid valves $\mathrm{V}_{4}$ and $\mathrm{V}_{5}$ switched on in the first attempt were set to $1.0 \mathrm{~s}$; thus, the volume of the sample solution slug $\left(\mathrm{Vs}_{1}\right)$ was equal to the volume of the titrant solution slug $\left(\mathrm{Vt}_{1}\right)(25.0 \mu \mathrm{L})$. The inner volume of the sampling loop $\left(\mathrm{L}_{1}\right)$ was $250 \mu \mathrm{L}$; thus, six sampling cycles were programmed to assure that the sampling loop was filled with a mix of sample and the titrant solutions. The time interval for the solenoid valve $\mathrm{V}_{3}$ switched on was $0.05 \mathrm{~s}$; therefore, six slugs $(1.25 \mu \mathrm{L})$ of the dye indicator solution were distributed throughout the sample zone. Afterwards, solenoid valves $\mathrm{V}_{1}, \mathrm{~V}_{3}, \mathrm{~V}_{4}$, and $\mathrm{V}_{5}$ were switched off, the pumping direction was reversed, and solenoid valves $\mathrm{V}_{2}$ and $\mathrm{V}_{6}$ were switched on. Under these conditions, the sample zone was displaced from the sampling loop by the carrier fluid (Cs) toward the photometer (Det). The reversing of the pumping direction improved the mixing between the titrant and titrand solutions, assuring an effective homogenization.

Prior to beginning the titration process, the signal generated by the photometer with the flow cell filled with the carrier fluid (Cs) was adjusted to ca. 2,000 mV $\left(\mathrm{V}_{0}\right)$. The signal generated with the flow cell filled with

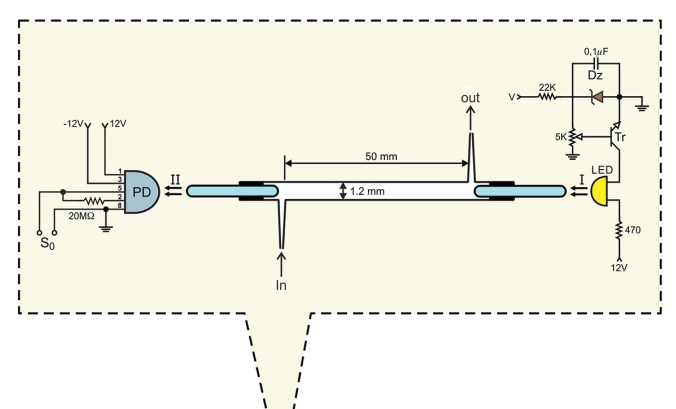

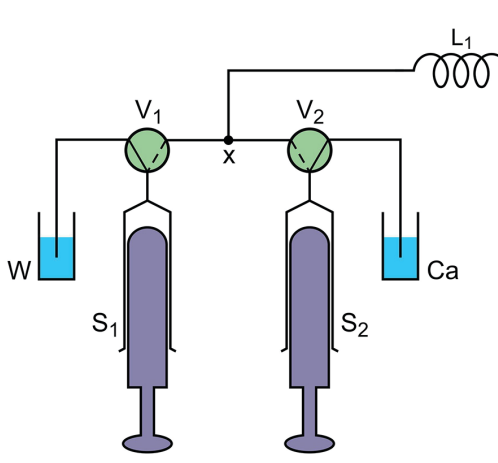

Figure 1. Diagram of the flow analysis module for photometric titration. $S_{1}$ and $S_{2}$ are the glass syringes; $x$ and $y$ are the fluid lines joint machined in PTFE; $\mathrm{V}_{1}$ and $\mathrm{V}_{2}$ are 3-way solenoid valves (100 psi); $\mathrm{V}_{3}, \mathrm{~V}_{4}, \mathrm{~V}_{5}$, and $\mathrm{V}_{6}$ are 2-way solenoid valves (normally closed) (30 psi); $\mathrm{L}_{1}$ and $\mathrm{L}_{2}$ are the sampling loop and connecting line (50 and $10 \mathrm{~cm}$ long, respectively); $\mathrm{W}$ is a waste bottle; $\mathrm{S}$, In, and Tit are the sample, indicators, and titrant solutions; and Ca is the carrier fluid (water). The insertion is the detection system employing an LED-based photometer. 
the sample should be lower than the measured value, $\mathrm{V}_{0}$. The microcomputer read the current signal $\left(\mathrm{V}_{\mathrm{i}}\right)$ generated by the photometer and subtracted it from the reference value $\left(\mathrm{V}_{0}\right)$ and analyzed its magnitude to determine the course of titration according to the following criteria: $(i)$ if the difference between the measurements $\left(\Delta \mathrm{mV}=\mathrm{V}_{0}-\mathrm{V}_{\mathrm{i}}\right)$ is lower than $150 \mathrm{mV}$, there is an excess of the titrand solution (acid medium) in the bulk sample; (ii) if $\Delta \mathrm{mV}$ is higher than $400 \mathrm{mV}$, there is an excess of the titrant solution (alkaline medium). If none of these conditions is met, the titration attains the stoichiometric condition and it should be finalized. The volumes of the sample and the titrant solutions to be used in the next titration attempt are defined considering the following conditions: volume variation $\Delta \mathrm{V}_{1}=\mathrm{Vs}_{1} / 2$ or $\Delta \mathrm{V}_{1}=\mathrm{Vt}_{1} / 2$; case $(i) \Delta \mathrm{mV}<150 \mathrm{mV}$, then the next sample volume is $\mathrm{Vs}_{2}=\mathrm{Vs}_{1}-\Delta \mathrm{V}_{1}$ and the next titrant solution volume is $\mathrm{Vt}_{2}=\mathrm{Vt}_{1}+\Delta \mathrm{V}_{1}$; case (ii) $\Delta \mathrm{mV}>400 \mathrm{mV}$, then $\mathrm{Vs}_{2}=\mathrm{Vs}_{1}+\Delta \mathrm{V}_{1}$ and $\mathrm{Vt}_{2}=\mathrm{Vt}_{1}-\Delta \mathrm{V}_{1}$. For the subsequent titration attempts, the volume variation was calculated as follow: $\Delta \mathrm{V}_{2}=\Delta \mathrm{V}_{1} / 2$ and $\Delta \mathrm{V}_{3}=\Delta \mathrm{V}_{2} / 2$ and so on until finding the end-point of the titration. The pumping flow rate was maintained at $25.0 \mu \mathrm{L} \mathrm{s}^{-1}$, thus the volumes of the solutions were achieved by varying the time intervals to switch on the solenoid valves $\mathrm{V}_{4}$ and $\mathrm{V}_{5}$.

\section{Results and Discussion}

\section{General comments}

The procedure for the acidity determination in fuel ethanol by photometric titration was implemented by employing a multicommuted flow analysis module and the binary search algorithm. The setup including the flow system module and the LED-based photometer (Figure 1) is designed to allow the automation of the methodologies recommended by $\mathrm{ANP}^{8}$ and $\mathrm{ASTM}^{9}$ to determine fuel ethanol acidity. The ANP procedure uses $\alpha$-naphtholphthalein as the color indicator, while the ASTM procedure uses phenolphthalein. The color indicators present spectral absorption at distinct wavelengths in acid and alkaline media (Figure 2). The spectra of the LEDs are within the absorption profile of the indicators. For the $\alpha$-naphtholphthalein indicator $\left(\lambda_{\max }=653 \mathrm{~nm}\right)$, a red LED with maximum emission at $647 \mathrm{~nm}$ was used (Figure 2A). For phenolphthalein, in alkaline medium $\left(\lambda_{\max }=550 \mathrm{~nm}\right)$, a green LED with maximum emission at $530 \mathrm{~nm}$ was efficient as a source of radiation (Figure 2B).

\section{Optimization of the experimental variables}

The proposed titration procedure exploited the binary sampling algorithm, in which the sampling flow rate and the volume of the sample and titrant solution exert a fundamental hole, so these parameters were the first studied. The hardware of the flow system was maintained as described in the caption of Figure 1. The connecting flow line $\left(\mathrm{L}_{2}\right)$ and the flow cell have inner volumes of 50 and $55 \mu \mathrm{L}$, respectively, considered the effective volume of the flow system. To work at the better sensitivity condition (less dispersion effect), the volume of the sample zone should be higher than $105 \mu \mathrm{L}$. Therefore, the volume of the sampling loop $\left(\mathrm{L}_{1}\right)$ was fixed at $250 \mu \mathrm{L}$.
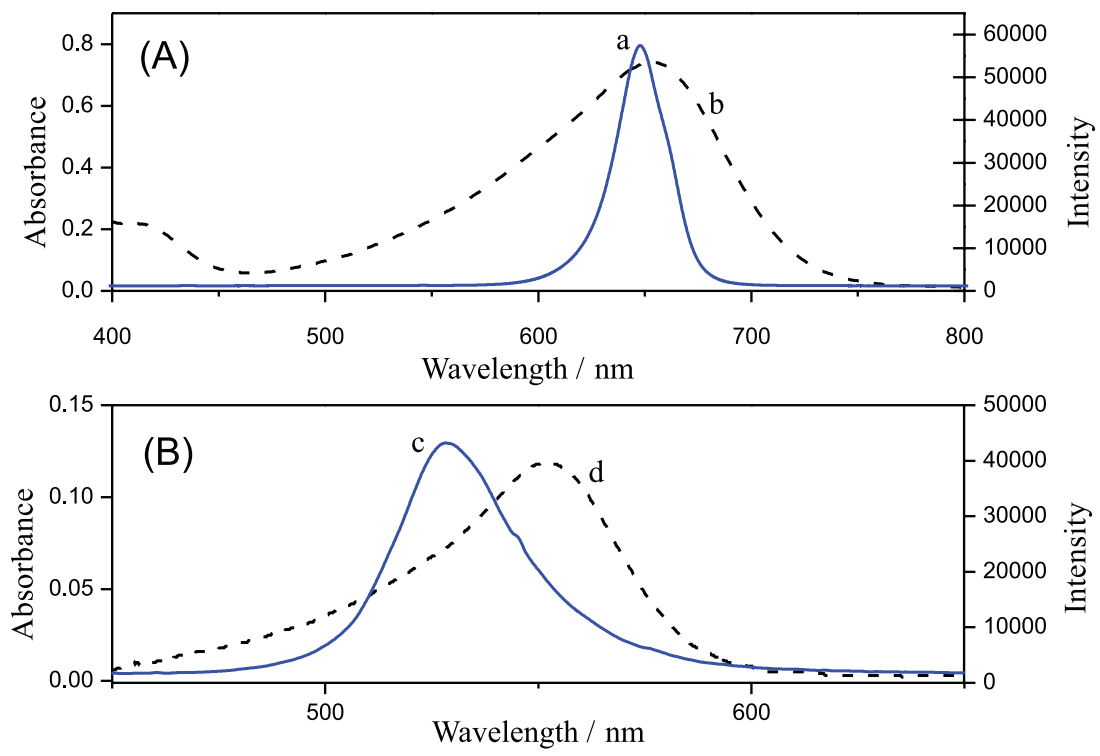

Figure 2. (A) and (B) correspond to the current procedures based on ABNT and ASTM methodologies, respectively. (b, d) Absorption spectra of the $\alpha$-naphtholphthalein and phenolphthalein in alkaline medium, respectively (50\% ethanol/water); (a, c) emission spectra of the red and green LEDs, respectively. These spectra were achieved with an Ocean Optics Spectrometer (USB4000-UV-Vis). 
The syringe pump used for fluid propulsion allowed pumping flow rates to be in the range of $3.2-200 \mu \mathrm{L} \mathrm{s}^{-1}$, which should be selected by the software. Preliminary assays carried out by titrating the ethanol solution of $50 \%$ $(\mathrm{v} / \mathrm{v})$, spiking it with the acetic acid solution $\left(5.0 \mathrm{mmol} \mathrm{L}^{-1}\right)$ and using a $10.0 \mathrm{mmol} \mathrm{L}^{-1} \mathrm{NaOH}$ titrant solution showed better results (coefficient of variation $<1 \%$ ). The results were achieved using a sampling flow rate of $25.0 \mu \mathrm{L} \mathrm{s}^{-1}$. This flow rate was selected to perform further assays. Aiming to speed up the analysis, the steps of the syringe filling and signal reading were carried out using the pumping flow rates of 200.0 and $100.0 \mu \mathrm{L} \mathrm{s}^{-1}$, respectively.

According to the binary search algorithm, ${ }^{15}$ while the sampling proceeded, the sampling loop $\left(\mathrm{L}_{1}\right.$, Figure 1) was loaded with a string of sample slugs in tandem with the slugs of the titrant solution. In order to minimize the dispersion effect, the number of sampling cycles must be sufficient to obtain a complete filling of the sampling loop $\left(\mathrm{L}_{1}\right)$. The sampling flow rate was set to $25.0 \mu \mathrm{L} \mathrm{s}^{-1}$ and for the first titration run, the time intervals to switch on solenoid valves $\left(\mathrm{V}_{4}, \mathrm{~V}_{5}\right)$ were $1.0 \mathrm{~s}$; thus, for each sampling cycle, $25.0 \mu \mathrm{L}$ of each solution was inserted into the sampling loop. The inner volume of the sampling loop was $250 \mu \mathrm{L}$. To assure a complete filling of the sampling loop, the number of sampling cycles should be at least six. Subsequent assays proved that an excess of $50 \mu \mathrm{L}$ was sufficient. For both indicator solutions (phenolphthalein $0.05 \%$ and $\alpha$-naphtholphthalein $0.01 \%(\mathrm{~m} / \mathrm{v}))$, the insertion time per sampling cycle was set at $0.05 \mathrm{~s}$, employing six sampling cycles; the consumption of indicators per titration attempt was $7.5 \mu \mathrm{L}$.

\section{Response of the setup in ethanolic medium}

According to the literature, ${ }^{22,23}$ in the flow analysis system, the schlieren effect can occur, while handling the ethanolic solution using water as the carrier fluid. Recently, this effect has been exploited for ethanol determination in samples of distilled beverages. ${ }^{24}$ Nevertheless, in the current work, the schlieren effect would cause a distortion of the measurements, which would prevent the correct identification of the titration end-point. Therefore, the possibility of this effect must be minimized. For this purpose, the samples of fuel ethanol were diluted with water to the ratio of $50 \%(\mathrm{v} / \mathrm{v})$. Aiming to evaluate if this expedient should be applied to analyze the real samples, a set of assays was performed using ethanolic standard solutions, which were spiked with a known amount of acetic acid, yielding the results presented in Table 1. The results are in good agreement with those achieved by employing the batch titrations as recommended by $\mathrm{ANP}^{8}$ and $\mathrm{ASTM}^{9}$ directives. Furthermore, the recovery is also within the acceptable range. These results indicate that the proposed setup has the potential to be used for the determination of acidity in fuel ethanol.

The titration was ended when the generated signal was within the preset range. Preliminary assays showed that for the titration of fuel ethanol, the threshold should be $150 \mathrm{mV}$, while the upper limit should be $400 \mathrm{mV}$. According to this criterion, the titration run was finished when the signal generated by the photometer was higher than $150 \mathrm{mV}$ and lower than $400 \mathrm{mV}$. The control software was designed to mimic the methodologies recommended by the $\mathrm{ASTM}^{9}$ and $\mathrm{ANP}^{8}$ regulatory agencies.

The records shown in Figure 3 were achieved following the ANP directive. After finishing the first titration run, the microcomputer analyzed if the number of attempts was higher than three, and when this happened, the next titration run resumes from the antepenultimate attempt. This strategy should save time to carry out the titration. In order to evaluate the usability of this strategy, the ethanol solution spiked with acetic acid $\left(5.05 \mathrm{mmol} \mathrm{L}^{-1}\right)$ was used as a model and the results are shown in Figure 3. These records show that for the first titration run, nine attempts were made to achieve a measurement within the preset range $(150 \mathrm{mV}<\Delta \mathrm{mV}<400 \mathrm{mV})$. The second titration run began at the antepenultimate attempt; thus, only three attempts $\left(g^{*}, h^{*}\right.$, and $\left.i^{*}\right)$ were made to attain the end-point of the titration. These results show that this strategy can be used to speed up the titration procedure, and, as a consequence, reduce the consumption of sample and titration solution, which become an additional advantage.

Table 1. Results of titration of ethanol standard solutions (50\% v/v)

\begin{tabular}{lcccc}
\hline Acetic acid added / $\left(\mathrm{mmol} \mathrm{L}^{-1}\right)$ & Batch / $\left(\mathrm{mmol} \mathrm{L}^{-1}\right)$ & MCFA / $(\mathrm{mmol} \mathrm{L}$ & & \multicolumn{2}{c}{ Recovery / \% } \\
\hline 10.0 & $10.45 \pm 0.14^{\mathrm{a}}$ & $10.65 \pm 0.92^{\mathrm{a}}$ & $104.5^{\mathrm{a}}$ & $106.5^{\mathrm{a}}$ \\
50.0 & $50.65 \pm 0.14^{\mathrm{a}}$ & $46.80 \pm 1.51^{\mathrm{a}}$ & $101.3^{\mathrm{a}}$ & $93.6^{\mathrm{a}}$ \\
5.0 & $5.30 \pm 0.20^{\mathrm{b}}$ & $5.29 \pm 0.35^{\mathrm{b}}$ & $106.0^{\mathrm{b}}$ & $105.8^{\mathrm{b}}$ \\
15.0 & $15.68 \pm 0.15^{\mathrm{b}}$ & $14.15 \pm 0.61^{\mathrm{b}}$ & $104.5^{\mathrm{b}}$ & $94.3^{\mathrm{b}}$ \\
\hline
\end{tabular}

Results are the average of three consecutive measurements \pm standard deviation. ${ }^{\mathrm{a}} \alpha$-Naphtholphthalein was used as an indicator; ${ }^{\mathrm{b}} \mathrm{phenolphthalein}$ was used as an indicator. MCFA: multicommuted flow analysis. 


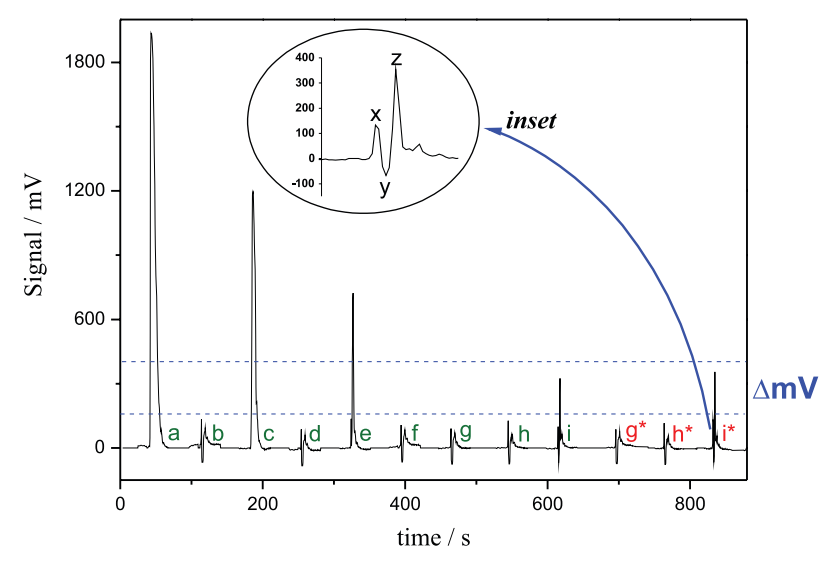

Figure 3. Records of the signals related to the proposed titration procedure. Experimental conditions were: $50 \%(\mathrm{v} / \mathrm{v})$ ethanol solution spiked with $5.05 \mathrm{mmol} \mathrm{L}^{-1}$ acetic acid; titrant solution, $10.0 \mathrm{mmol} \mathrm{L}^{-1}$ $\mathrm{NaOH}$; solutions insertion step, six sampling cycles; and threshold $(150<\Delta \mathrm{mV}<400 \mathrm{mV})$. (a-i) Records of the signals generated by mimicking the ANP recommendation at the first titration run; $\left(\mathrm{g}^{*}, \mathrm{~h}^{*}, \mathrm{i}^{*}\right)$ related to the second run. Inset shows the schlieren effect $(x, y)$ and the analytical measurement (z).

The schlieren effect due to mixing fluids with different refractive indices could impair the correct detection of the titration end-point. The records in Figure 3 confirm that this effect occurred. Analyzing these records, we observe that the magnitude of the signals related to the schlieren effect is lower than the threshold value that was preset to $150 \mathrm{mV}$, therefore, this effect does not affect the decision concerning to the end-point of the titration. Nevertheless, the inset shows that the analytical measurement (z) is preceded by a negative signal, which occurred for all titration attempts with measurement lower than $400 \mathrm{mV}$. This feature is due to schlieren effect, ${ }^{25}$ thus the detection of signal with negative polarity was included to the control software as a parameter to help the detection of the titration end-point.

The control software was instructed to perform the first attempt of titration, switching the solenoid valves that handled titrant and titrand solutions for a time interval of
$1.0 \mathrm{~s}$. According to the binary search algorithm, ${ }^{15}$ the course of titration to find the stoichiometric point was found by evaluating the magnitude of the signal generated by the photometer. The time intervals and the corresponding volumes of titrant and titrand solutions inserted in the sampling loop (Figure 1), while performing the titration as depicted in Figure 3, are summarized in Table 2. The results show that the ultimate variation of the titrant solution volume was $0.59 \mu \mathrm{L}$. The sample zone volume was close to $300 \mu \mathrm{L}$; therefore, it was 500 -fold higher than the volume variation $(0.59 \mu \mathrm{L})$. The photometer could still generate a signal within the established range.

\section{Determination of acidity in sample of fuel ethanol}

Aiming to evaluate the effectiveness of the proposed procedure to determine the acidity of fuel ethanol, a set of samples acquired at the local market was analyzed. For the accuracy assessment, samples were analyzed by employing the $\mathrm{ANP}^{8}$ and $\mathrm{ASTM}^{9}$ reference methodologies and the results are presented in Table 3. The Student's $t$-test for paired samples at the $95 \%$ confidence level $(n=4)$ revealed the values of 1.58 and 1.32 for the ANP and ASTM methodologies, respectively. The critical $t$-value was 2.78 , indicating no significant differences between the results.

\section{Figure of merit and performance comparison}

The fluid propelling setup, designed to be controlled by the microcomputer, allowed the handling of solution volumes at a wide range, without impairing the precision of sampled aliquots that is a parameter essential to titration methodologies. The LED-based photometer presented a low-level noise and effective long-term stability; thus, the titration signal range was updated once a day when it was powered. Low values of standard deviation $(<1 \%$,

Table 2. Values of the variables while performing a titration run

\begin{tabular}{|c|c|c|c|c|c|c|c|}
\hline Attempt & time titrand / $\mathrm{s}$ & time titrant / s & Variation / s & Titrand / $\mu \mathrm{L}$ & Titrant / $\mu \mathrm{L}$ & Signal / mV & Sample / $\left(\mathrm{mmol} \mathrm{L}^{-1}\right)$ \\
\hline $\mathrm{a}$ & 1.0 & 1.0 & - & 150.00 & 150.00 & $>\Delta \mathrm{mV}$ & 10.00 \\
\hline $\mathrm{b}$ & 1.5 & 0.5 & 0.50 & 225.00 & 75.00 & $<\Delta \mathrm{mV}$ & 3.33 \\
\hline $\mathrm{c}$ & 1.25 & 0.75 & 0.250 & 187.50 & 112.50 & $>\Delta \mathrm{mV}$ & 6.00 \\
\hline $\mathrm{d}$ & 1.375 & 0.625 & 0.1250 & 206.25 & 93.75 & $<\Delta \mathrm{mV}$ & 4.55 \\
\hline $\mathrm{e}$ & 1.312 & 0.688 & 0.0625 & 196.88 & 103.13 & $>\Delta \mathrm{mV}$ & 5.24 \\
\hline $\mathrm{f}$ & 1.343 & 0.656 & 0.0313 & 201.56 & 98.44 & $<\Delta \mathrm{mV}$ & 4.88 \\
\hline $\mathrm{g}$ & 1.328 & 0.672 & 0.0156 & 199.22 & 100.78 & $<\Delta \mathrm{mV}$ & 5.06 \\
\hline $\mathrm{h}$ & 1.320 & 0.680 & 0.0078 & 198.05 & 101.95 & $<\Delta \mathrm{mV}$ & 5.15 \\
\hline $\mathrm{i}$ & 1.316 & 0.684 & 0.0039 & 197.46 & 102.54 & $\Delta \mathrm{mV}$ & 5.19 \\
\hline
\end{tabular}

These variable values refer to Figure $3 ; \Delta \mathrm{mV}$ : net signal generated by the photometer; >: $\Delta \mathrm{mV}$ higher than $400 \mathrm{mV} ;<: \Delta \mathrm{mV}$ lower than $150 \mathrm{mV}$. 
Table 3. Results of determination of acidity in fuel ethanol

\begin{tabular}{lcccc}
\hline \multirow{2}{*}{ Sample } & \multicolumn{4}{c}{ Acidity / (mg of acetic acid per liter of ethanol) } \\
\cline { 2 - 5 } & MCFA $^{\mathrm{a}}$ & Titration-batch $\left(\right.$ ANP) $^{\mathrm{a}}$ & MCFA $^{\mathrm{b}}$ & ${\text { Titration-batch }(\text { ASTM })^{\mathrm{b}}}^{\text {A }}$ \\
\cline { 2 - 5 } B & $6.92 \pm 0.28$ & $10.08 \pm 0.58$ & $9.52 \pm 0.09$ & $10.82 \pm 0.72$ \\
C & $6.6 \pm 0.9$ & $6.9 \pm 0.3$ & $9.1 \pm 0.1$ & $8.98 \pm 0.45$ \\
D & $20.2 \pm 0.1$ & $17.2 \pm 0.3$ & $20.10 \pm 0.05$ & $21.32 \pm 0.27$ \\
E & $18.98 \pm 0.41$ & $16.58 \pm 0.25$ & $20.01 \pm 0.05$ & $19.29 \pm 0.63$ \\
\hline
\end{tabular}

Results are the average of three consecutive measurements \pm standard deviation. ${ }^{\mathrm{a}} \boldsymbol{\alpha}$-naphtholphthalein as color indicator; ${ }^{\mathrm{b}}$ phenolphthalein as color indicator. MCFA: multicommuted flow analysis.

$\mathrm{n}=6$ ) using an ethanol fuel sample with $0.34 \mathrm{mmol} \mathrm{L}^{-1}$ acetic acid, low reagent consumption, and high sampling rate ( $\geq 10$ determination per hour) compared with manual titration processes are the advantages of the current work. In addition, the end-point detection performed by a photometer is more accurate than that obtained by visual observations, resulting in better precision of the results. The time interval to perform a titration with nine attempts is $10.8 \mathrm{~min}$ (Figure 3). Considering that the sample analysis is performed in triplicate, resorting to the shortcut strategy described before, the system should perform the analysis in ca. $18.0 \mathrm{~min}$. Under this condition, the volume of the waste generated was $11.5 \mathrm{~mL}$ per determination, which is approximately ten times lower than the waste volume generated by employing either ABNT or ASTM methodology.

Aiming to perform a comparison with existing procedures for acidity determination in fuel ethanol, the main parameters usually used for this end were summarized in Table 4, where we can observe that recovery and coefficient of variation are similar with those papers, while waste generated per determination is lower. The paper ${ }^{10}$ referred at the second line of the Table 4, presents a sampling rate of 120 determination per hour, nevertheless it was implemented using a strip-chart recorder to record the signal profile, thus additional measurements of peak-height were mandatory prior to obtain the acid concentration.
This task carried out manually consumes a long time, and furthermore it could become a source of error. While using the proposed procedure at the end of each titration run, the computer displayed on the screen the volumes of titrant and titrand solutions used, as well as the acid concentration of sample. Additionally, the results were saved in a file to allow further analysis. The linear correlation coefficients displayed in Table 4 show that the results obtained with the proposed procedure present a close agreement with those obtained using ANP and ASTM methodologies.

\section{Conclusions}

The results demonstrate the feasibility of the proposed titration procedure, implemented by employing the binary search strategy to determine the acidity of samples of fuel ethanol. The proposed procedure could become a viable alternative to the methodologies established by the regulatory agencies ANP and ASTM. The interference that could be caused by $\mathrm{CO}_{2}$ was overcome using freshly boiled water. Since titration proceeded in a closed environment, the additional use of gases such as nitrogen $\left(\mathrm{N}_{2}\right)$ was not necessary, which would be considered as a comparative advantage over manual procedures. ${ }^{8,9}$

The robustness was evaluated using ethanol solutions spiked with acetic acid, which were titrated using standardized $\mathrm{NaOH}$ solutions. The assay was carried out

Table 4. Performance comparison with existing procedures for acidity determination in ethanol fuel

\begin{tabular}{|c|c|c|c|c|c|}
\hline $\mathrm{CV} / \%$ & Recovery / \% & Waste $^{\mathrm{a}} / \mathrm{mL}$ & Sampling rate $/ \mathrm{h}^{-1}$ & $\mathrm{r}^{\mathrm{c}}$ & Reference \\
\hline$<1(\mathrm{n}=6)$ & $93.6-106.5$ & $\leq 11.5$ & $\geq 10$ & $\begin{array}{l}0.9978^{\mathrm{d}} \\
0.9880^{\mathrm{e}}\end{array}$ & this work \\
\hline$<1(\mathrm{n}=15)$ & $97.6-102.7$ & 15.5 & 120 & 0.9991 & 10 \\
\hline$<3$ & $98.7-102.7$ & $>100$ & - & - & 11 \\
\hline$<1$ & - & $>12$ & - & - & 12 \\
\hline
\end{tabular}

${ }^{\mathrm{a}}$ Waste generated per determination, ${ }^{\mathrm{b}}$ determinations per hour, ${ }^{\mathrm{c}}$ linear correlation coefficient achieved by plotting the results of the proposed procedures versus those of the reference methods; ${ }^{\mathrm{d}} \mathrm{ANP}$ methodology; ${ }^{\mathrm{e}} \mathrm{ASTM}$ methodology. CV: coefficient of variation. 
consecutively for five days $(n=5)$ and the results presented a coefficient of variation of less than $4 \%$, which should be considered an indication of robustness. The proposed procedure represents a step forward in the automation of the acidity determination in fuel ethanol by employing photometric titration without using analytical curves. In this sense, this procedure meets the IUPAC ${ }^{26}$ definition of true titration. Furthermore, the volume of waste generated was approximately ten times lower than the volume of waste produced by using the ABNT or ASTM methodologies; therefore, the current procedure also meets the analytical green chemistry recommendation concerning the waste reduction. ${ }^{27}$

\section{Acknowledgments}

This work is supported by the Brazilian funding agencies CNPq (process No. 165478/2015-2, 309036/2016-0), CAPES, FAPESP (process No. 2011/23498-9), and INCTAA (process No. CNPq 573894/2008-6).

\section{References}

1. Mota, C. J. A.; Monteiro, R. S.; Quim. Nova 2013, 36, 1483.

2. Cheng, J. J.; Timilsina, G. R.; Renewable Energy 2011, 36, 3541.

3. Hammerschlag, R.; Environ. Sci. Technol. 2006, 40, 1744.

4. Cheng, J. J.; Timilsina, G. R.; Renewable Energy 2011, 36, 3541 .

5. Teixeira, L. S. G.; Brasileiro, J. F.; Borges Jr., M. M.; Cordeiro, P. W. L.; Rocha, S. A. N.; Costa, A. C. S.; Quim. Nova 2006, 29, 741 .

6. Stradiotto, N. R.; Zanoni, M. V. B.; Fraga, I. C. S.; Borges, P. P. In Sugarcane Bioethanol - R\&D for Productivity and Sustainability; Cortez, L. A. B., ed.; Edgard Blücher: São Paulo, 2014, p. 813.

7. Teixeira, L. S. G.; Chaves, T. J.; Guimarães, P. R. B.; Pontes, L. A. M.; Teixeira, J. S. R.; Anal. Chim. Acta 2009, 640, 29.

8. ABNT NBR 9866: Fuel Ethanol - Determination of Total Acidity by Colorimetric Titration, Associação Brasileira de
Normas Técnicas, Rio de Janeiro, 2012. Available at https:// goo.gl/s7o99v, accessed in May 2018.

9. ASTM D1613-17: Standard Test Method for Acidity in Volatile Solvents and Chemical Intermediates Used in Paint, Varnish, Lacquer, and Related Products, ASTM International, West Conshohocken, PA, 2017.

10. Fatibello-Filho, O.; Borges, M. T. M. R.; Anal. Chim. Acta 1998, 366,81 .

11. Avelar, H. M.; Barbeira, P. J. S.; Fuel 2007, 86, 299.

12. Gonzaga, F. B.; Gonçalves, M. A.; Sobral, S. P.; Ribeiro, C. M.; Fuel 2012, 94, 70.

13. Oliveira, M. F.; Saczk, A. A.; Okumura, L. L.; Stradiotto, N. R.; Energy Fuels 2009, 23, 4852.

14. Soares, V. R. B.; Rocha, F. R. P.; Teixeira, L. S. G.; Anal. Lett. 2013, 46, 1621.

15. Korn, M.; Gouveia, L. F. B. P.; Oliveira, E.; Reis, B. F.; Anal. Chim. Acta 1995, 313, 177.

16. Rodenas-Torralba, E.; Reis, B. F.; Morales-Rubio, A.; de la Guardia, M.; Talanta 2005, 66, 591.

17. Dias, T. R.; Reis, B. F.; Anal. Methods 2016, 8, 3620.

18. Pereira, A. C.; Rocha, F. R. P.; Anal. Chim. Acta 2014, 829, 28.

19. Piston, M.; Silva, J.; Perez-Zambra, R.; Dol, I.; Knochen, M.; Environ. Geochem. Health 2012, 34, 273.

20. Santos, F. G.; Reis, B. F.; J. Anal. Methods Chem. 2017, 2017, Article ID 9361460.

21. Lima, M. J. A.; Reis, B. F.; Talanta 2017, 164, 183.

22. Rocha, F. R. P.; Nóbrega, J. A.; Quim. Nova 1996, 19, 636.

23. Dias, A. C. B.; Borges, E. P.; Zagatto, E. A. G.; Worsfold, P. J.; Talanta 2006, 68, 1076.

24. Silva, D. S.; Reis, B. F.; Microchem. J. 2016, 129, 325.

25. Santos, S. R. B.; Araújo, M. C. U.; Barbosa, R. A.; Analyst 2002, 127, 324.

26. International Union of Pure and Applied Chemistry (IUPAC); Compendium of Analytical Nomenclature, Definitive Rules 1997, $3^{\text {rd }}$ ed.; Blackwell Scientific Pub: Oxford, UK, 1998.

27. Armenta, S.; Garrigues, S.; de la Guardia, M.; TrAC, Trends Anal. Chem. 2008, 27, 497.

Submitted: March 6, 2018

Published online: June 8, 2018 